\title{
LO OMINOSO: ESTÉTICA Y SUBJETIVACIÓN HISTÓRICA EN LA LITERATURA GÓTICA Y EL PSICOANÁLISIS
}

\section{THE UNCANNY: AESTHETIC AND HISTORICAL SUBJECTIVATION IN GOTHIC LITERATURE AND PSYCHOANALYSIS}

\section{JOSÉ CABRERA SÁNCHEZ*}

Resumen: Tomando como eje argumental el concepto de lo ominoso, se explora la construcción teórica de este término durante la Ilustración, y su incidencia tanto en la literatura gótica moderna como en la obra freudiana de comienzos del siglo XX. La hipótesis desarrollada es que este concepto tiene una especificidad histórica y que su inclusión como engranaje estructural, tanto en la ficción gótica como en el discurso psicoanalítico, da cuenta de fenómenos de representación cuyo análisis permite una aproximación crítica a los marcos epistémicos y a los efectos de subjetivación movilizados por el espíritu iluminista.

Palabras clave: Ominoso, literatura gótica, psicoanálisis, subjetivación, Ilustración.

AвSTRACT: This article explores the development of the concept of the uncanny during the Enlightenment, as well as its appearance in modern gothic literature and the work of Sigmund Freud in the twentieth century. This study argues that the uncanny is a historically situated concept whose use as a structuring mechanism, both in gothic fiction and psychoanalytic discourse, reveals a mode of representation that allows for a critical approach to the epistemic framework and subject effects mobilized by Enlightenment thought.

KEYWORDs: The uncanny, gothic literature, psychoanalysis, subjectivation.

Recibido: 02.04.2019. Aceptado: 25.03.2020

\section{INTRODUCCIÓN}

T o ominoso alude a una sensación de pérdida de familiaridad que apaLrece en el núcleo mismo de lo conocido, o bien, según una inversión

* Doctor en Psicoanálisis. Profesor Instituto de Psicología, Universidad Austral de Chile, Puerto Montt, Chile. Correo electrónico: jcabrera@spm.uach.cl. Orcid: https://orcid.org/0000-0002-44639741. 
especular de la misma definición, se trataría de una experiencia de familiaridad que asoma en el centro de lo desconocido. A diferencia de otras formas de lo terrorífico o lo inquietante, lo ominoso alude a un modo del vivenciar que nos expone a una suerte de subversión en la experiencia de lo cercano y conocido, una torsión de la vivencia estético-emocional en que las categorías de lo íntimo y lo ajeno o, de lo interno y externo, dejan de operar como demarcadores clásicos de la distinción sujeto/objeto, no para escindirse como si se tratara de dos planos inconciliables, sino para exponer una solución de continuidad que los vuelve inseparables. Desde esta perspectiva, lo ominoso sería una variedad de la experiencia estética en que lo de antiguo conocido súbitamente adquiere el cariz de lo extranjero, teniendo como efecto la turbadora sensación de que aquello que era considerado próximo y familiar se vea teñido con los tonos de lo desconocido e inquietante.

Para Andrew Bennet y Nicholas Royle (2009), lo ominoso se relaciona con la literatura según un doble vínculo; por un lado, lo ominoso se presentaría en la vida cotidiana cuando inesperadamente nuestra rutina se ve perturbada por una sensación de estupefacción amenazante, en lo que podría llamarse una interferencia estética que trastoca el vivenciar según las cualidades literarias o ficcionales de la desrealización y la despersonalización; por otro lado, sería factible definir la literatura misma como un discurso de lo ominoso, en tanto, tal como lo expusieron los formalistas rusos, opera según un principio de desfamiliarización, es decir, "hace que lo familiar sea extraño, desafía nuestras creencias y suposiciones sobre el mundo y sobre la naturaleza de la 'realidad'” (Bennet y Royle, 2009, p. 36, traducción propia).

\section{LOS ESTRATOS HISTÓRICOS DE LO OMINOSO}

Tomaremos esta equivalencia entre la literatura y lo ominoso como un punto de partida, una hipótesis intempestiva para poner en marcha la argumentación. Esta conjetura apresurada, si bien no del todo desencaminada, requiere de una puntualización que la haga viable. Si por lo ominoso en la literatura entendemos la operación de un principio de desfamiliarización que sería el mecanismo que atraviesa y moviliza sus diversas formas de organización retórica, inscripción representacional y estructuración narrativa, evidentemente caeríamos en una generalización al aplicar este principio de forma inespecífica, error que, desde la perspectiva que desarrollaremos, 
se fundamenta en no considerar una estratificación epocal y estilística que permita distinguir las diferentes modalidades adquiridas por la producción literaria en el marco de sus transformaciones históricas.

Ahora bien, si tomamos en consideración lo que acabamos de señalar, podemos volver a situar la proposición de Bennet y Royle (2009) como una hipótesis inicial, pero esta vez cuidándonos de establecer la pertinencia histórica de dicha conjetura. Tal es la orientación que por ejemplo encontramos en el trabajo de David Ellison (2001), quien al encarar el análisis del lugar que ocupa lo ominoso en la representación literaria propone una distinción histórica. Para este teórico, la irrupción de lo ominoso como engranaje articulador de la construcción ficcional literaria puede ser ubicado en el umbral que se abre entre el imperio de la sensibilidad romántica y el advenimiento del modernisme, un momento que, según su perspectiva, se situaría hacia comienzos del siglo XX. Según Ellison, los escritores asociados al modernisme habrían descubierto lo literario como tal precisamente al caer en el territorio de lo ominoso, cuestión patente en la obra de literatos como Marcel Proust o Franz Kafka, en quienes el despliegue narrativo resulta inseparable de una especie de reverberación siniestra que pareciera provenir desde el interior de las propias palabras.

La reflexión sobre los marcos históricos de lo ominoso, entendido este último como un concepto que atestigua sobre formas de inscripción que son tanto estéticas como subjetivantes, ha tenido un desarrollo conceptual bastante pródigo en las últimas décadas del siglo pasado, cuestión que llevó a Martin Jay (1998) a calificar este período como los "ominosos 90", para referirse a la profusión de trabajos en el campo de la crítica literaria, artística y cultural que se consagraron a este tópico durante este periodo. Para Jay, resulta llamativo que durante la primera mitad del siglo pasado el análisis de la categoría de lo ominoso haya quedado en lo fundamental reducido al ensayo de Sigmund Freud "Lo ominoso" (Das Unheimliche), el que incluso entre los propios estudiosos de la obra freudiana recibió muy poca atención ${ }^{1}$.

\footnotetext{
${ }^{1}$ Jacques Lacan (2007a) es uno de los pocos psicoanalistas que le dieron importancia conceptual a lo ominoso antes de que este término cobrara relevancia entre los teóricos literarios. Para Lacan la experiencia de lo ominoso es el efecto de la aparición sorpresiva de un objeto en el lugar que debería estar ocupado por el soporte imaginario de la castración. La angustia, tradicionalmente comprendida como el efecto de un vacío o ausencia, es pensada por Lacan apuntalándose en la teoría freudiana de lo ominoso, lo que le permite concluir que esta, y por tanto la vivencia ominosa, son consecuencia de una presencia o exceso, la que debe entenderse como el develamiento de un objeto que debía permanecer oculto bajo una representación imaginaria de la falta.
} 
A comienzos de la década del 70, de la mano de Hélène Cixous (1976) y Jacques Derrida (1997), este concepto vendrá a encontrar un renovado interés, primero entre los críticos literarios de inspiración postestructuralista, y después dentro del campo de la teoría del arte y la crítica cultural.

Se le suele atribuir a Edmund Burke (1998) el haber dado inicio a una conceptualización moderna de lo ominoso como categoría relevante de la experiencia estética. Sin embargo, no es del todo evidente que el ensayo de Burke se consagre de forma privilegiada a inspeccionar los mecanismos que dan forma a la vivencia de lo ominoso, al menos en lo que respecta a los dos conceptos que en el título de su tratado se enuncian como los objetos que somete a examen: lo sublime ${ }^{2}$ y lo bello. No obstante, la disección interpretativa de lo sublime efectuada por Burke expone el inesperado esqueleto que sostiene este, aparentemente, evanescente concepto. Allí donde se esperaría encontrar algo más afín a lo luminoso o lo cristalino, o alguna configuración retórica que aluda a lo elevado y excelso, Burke da con la nervadura orgánica y la materialidad objetual que condicionarían la experiencia de lo sublime. Para Terrence Des Pres (1983), la concepción de Burke sobre lo sublime se distancia profundamente de la desarrollada por Pseudo-Longinus en su seminal Peri Hypsous (Sobre lo sublime), ya que para este último la condición de lo sublime es resultado de un acto de estructuración retórica, es decir, se trataría de una categoría estética que se deriva de una determinada composición estilística y figurativa; de forma contrastante, Burke concibe lo sublime como una experiencia que concierne tanto a ciertos objetos y configuraciones ambientales, como al efecto perceptivo que estas inducen en el sujeto receptor. Lo que para PseudoLonginus era consecuencia de una particular articulación significante, es pensado por Burke desde un materialismo organicista, en el cual la experiencia estética es una emanación epifenoménica de los sistemas perceptivos del cuerpo impactados por la magnitud inconmensurable de ciertos estímulos (Morris, 1985).

Si bien el análisis de Burke descansa sobre una perspectiva epistémica de una ingenuidad cuasi biológica - profundamente distanciada de lo re-

\footnotetext{
${ }^{2}$ La reflexión literaria sobre lo sublime tiene un temprano antecedente en el ensayo Peri Hypsous, atribuido a Pseudo-Longinus, y que dataría del siglo I después de Cristo. Este ensayo se hizo conocido a través de la traducción del francés Nicolás Boileau, de 1672, a la que se le atribuye gran relevancia en la configuración de la estética barroca. El ensayo de Pseudo-Longinus es referenciado por Burke en el prefacio de la primera edición de A philosophical enquiry into the origin of our ideas of the sublime and beautiful (Axelsson, 2007), lo que evidencia su conocimiento de este clásico tratado sobre lo sublime. Existe una traducción del texto de Pseudo-longinus al español De lo sublime (2007), realizada por Eduardo Molina y Pablo Oyarzún.
} 
tórico- produjo una fisura en el cuerpo conceptual de la estética que fue colonizada por las reformulaciones románticas de lo sublime; esta grieta argumentativa se deriva de la continuidad experiencial que la comprensión de Burke tiende entre las concepciones de lo sublime y lo ominoso, relación que se fundamenta en lo que sería la fuente última de la experiencia de lo sublime: el horror.

La caracterización de Burke de la experiencia de lo sublime coincide con un horror que tendría su fundamento en la dificultad o imposibilidad del sujeto para representarse una experiencia que, por oscura, poderosa o descomunal, lo deja sumido en el desconocimiento y la perplejidad. Esta fundamentación de lo sublime como un arrobamiento de la conciencia en la totalidad excesiva del objeto, puede ser interpretado como el gesto conceptual que abre la puerta para una mutación histórica de la significación estética de lo ominoso. Esta conexión contraintuitiva entre lo terrorífico y lo sublime es refrendada por Immanuel Kant, tal como queda de manifiesto en Observaciones sobre el sentimiento de lo bello y lo sublime (2005); no obstante, esta coincidencia inicial sufrirá una significativa mutación conceptual, por efecto del distanciamiento crítico de Kant respecto del empirismo de la propuesta de Burke. En su Crítica del juicio (2007), Kant, al establecer el papel de la razón como medio de trascendencia de lo sensible, se aleja del materialismo objetual al que se ancla la noción de lo sublime en Burke. Si bien Kant aún coincide con Burke al considerar que la experiencia de lo sublime deriva del encuentro con fenómenos de gran magnitud o potencia (lo que diferencia según las modalidades respectivas de lo "sublime matemático" y lo "sublime dinámico"), concebirá lo sublime no como una propiedad que emana del objeto, sino como el efecto de un juicio estético que atestigua sobre el fracaso de la fantasía para abarcar la grandiosidad del fenómeno (Oroño, 2017); sin embargo, este fracaso de la imaginación da pie a su propia superación, en tanto el tropiezo de la intuición sensible abre el camino a la facultad suprasensible de la razón, permitiéndonos pensar lo infinito aun cuando este exceda nuestra sensibilidad.

Para Morris (1985), el modo de concebir lo sublime propuesto por Burke refleja el espíritu del siglo XVIII, un espíritu que aún se encuentra anclado a sentidos relativamente estables y para el cual la interpretación no jugaba un papel relevante. Sin embargo, la teoría del terror desplegada por Burke habría despejado el terreno para que el problema de la articulación retórica del sentido volviera a encontrar un espacio de inscripción estética. El aporte de Kant en la formación de esta nueva sensibilidad estética resulta fundamental, dado que su conceptualización de la experiencia sublime 
supone la superación por medio de la facultad suprasensible de lo que, en la perspectiva de Burke, no sería más que una estrecha cuenta mecánica de procesos corporales (Morris, 1985).

Burke, sin proponérselo, abrió un espacio para que retornasen los espectros de la indeterminación que la luz de la razón ilustrada creía haber desalojado. Dando a entender que la ficción gótica supone una suerte de retorno de algo previamente excluido, Deidre Shauna Lynch (2008) concluye que esta "volvió a familiarizar a esa población con los placeres perversos de la incertidumbre" (p. 47, trad. propia). Tal reinscripción no solo es indicativa de un retorno melancólico al pasado, ya que introduce un novedoso modo de goce estético.

Como lo ha hecho ver Mladen Dolar (1991), existe una dimensión específica de lo ominoso que emerge con la modernidad; en las sociedades pre-modernas lo ominoso se encontraba velado tras lo sagrado, espacio de privilegio y exclusión del que habría sido desalojado con el advenimiento de la Ilustración. Con ello lo ominoso pasó a ocupar una dimensión de visibilidad que lo llevó a alcanzar su genuino estatuto, es decir, constituirse en una forma de extrañeza capaz de desfigurar de modo perturbador la apariencia de lo supuestamente conocido.

¿Cómo interpretar este florecimiento de imágenes y símbolos que parecen contradecir el espíritu de una época que quería dejar atrás el temor tanto a las fuerzas insensatas de lo divino, como a los condicionamientos irreflexivos de la naturaleza?

La estrategia estética del gótico moderno no fue la de exponer de una manera crítica y explícita aquellos contenidos que resultaban indignos a la conciencia iluminista, sino que bajo la forma de una estilística que remitía a diversas tradiciones pre-modernas, vino a generar la ilusión de un pasado mítico en el cual se hundían las raíces de los tópicos que dieron forma a su canon. Tal remisión a un pasado originario puede ser comprendida desde la lógica de la retroactividad freudiana (Nachträglichkeit), es decir, como la construcción ficcional de un momento pasado al que se le atribuye una condición de origen que en términos positivos nunca tuvo lugar. El origen arcaico que el gótico moderno quisiera encontrar en tradiciones pretéritas no es más que una reconstrucción fantasmática que tiene que ver con las angustias culturales modernas más que con un sentido sólidamente constituido en un pasado rememorado con nostalgia. Como lo ha hecho ver Derrida (1989), los textos de lo inconsciente pueden ser pensados como "depósitos de un sentido que no ha estado nunca presente, cuyo presente significado es siempre reconstituido con retardo, nachträglich, a destiempo" 
(p. 291). Si consideramos la literatura gótica como la representación textual de un "inconsciente epocal", podemos concluir que los escenarios y símbolos del pasado que actúan como soporte argumental de la novela gótica, no son sino la construcción mítica de un fundamento originario. De esta forma lo hace ver Fred Botting (1999), cuando señala que "el gótico es una huella originaria, una historia fabricada, una fantasía de orígenes culturales y familiares que diferidamente -suplementariamente- se inscribe a sí misma" (p. 21, trad. propia).

Jerrold Hogle (2014), un importante estudioso de la literatura romántica inglesa, se refiere a las fuerzas antagónicas que recorren un libro como El castillo de Otranto, publicado en 1764 por Horace Walpole y considerado como el texto inaugural del terror gótico. Para Hogle el calificativo de moderno utilizado por Walpole debe ser interpretado como un reflejo de las aspiraciones de la clase media que comienza a emerger en dicha época, una clase profundamente preocupada por los anhelos ideológicos de la creciente burguesía y que intentaba romper con los previos absolutismos religiosos y políticos. Por otra parte, la dimensión clásica de la novela de terror gótico, según Hogle, es realmente un pastiche de diversas referencias (elementos shakesperianos, operáticos, medievales, que aparecen unidos a fragmentos de motivos espirituales griegos y católicos), que teniendo poco de antiguo busca condensar una serie de ansiedades culturales que encuentran su expresión en el compendio híbrido del gótico moderno. De este modo, la imaginación gótica parece dar cuenta del acoso de fuerzas contramodernas, fuerzas amenazantes que socavan el ideal de una subjetividad que se supone capaz de dejar atrás las tendencias regresivas que impiden el progreso del ideal iluminista (Hogle, 2014). El pastiche estético de la literatura gótica compuso una serie de imágenes que por un efecto de fetichización parecían referir a un pasado idealizado que tiene mucho más de mito que de realidad, tal como lo indica Botting (2012): "los paisajes salvajes, los castillos y abadías en ruinas, los laberintos oscuros y húmedos, los eventos maravillosos y sobrenaturales, los tiempos y las costumbres lejanas" no solo resultan imágenes de un supuesto pasado ya abandonado, "sino que también introducen las pasiones, los deseos y las emociones que [la Ilustración] reprime" (p. 19).

Es necesario tomar un recaudo en relación con atribuirle a la ficción gótica la capacidad de revelar ciertos contenidos que yacerían en una cierta "profundidad" cultural a la cual habrían sido relegados por el espíritu ilustrado. Eve Sedgwick (1981), refiriéndose a tal vicio interpretativo de la crítica literaria, señala que esta ha tendido a utilizar metáforas espacia- 
les que remiten a la idea de interioridad para sustentar sus análisis, lo que implica una mala comprensión tanto de las ideas freudianas, que inspiran tales interpretaciones, como de la estética gótica, ya que en ambos casos la dimensión topográfica debe ser entendida como un mecanismo de representación que juega sobre la superficie discursiva y no dentro de una supuesta profundidad subjetiva.

En una línea coincidente con Sedgwick, Botting (1999) sostiene que lo que caracteriza a la literatura gótica es su falta de profundidad (depthlessness). La tesis desarrollada por Foucault (2010) en Las palabras y las cosas, le permite a Botting dar cuenta de la lógica discursiva y epistémica que encarna la ficción gótica, donde el parentesco entre el conocimiento y el lenguaje -característico del pensamiento clásico- se disuelve hasta transformarse en una relación que expone "un saber cerrado sobre sí mismo y un lenguaje puro convertido, en su ser y su función, en enigmático -algo que, a partir de esta época, se llama literatura" (Foucault, 2010, p. 94). Las ideas de Foucault le permiten a Botting desarrollar la hipótesis de que la ficción gótica fue una de las formas que permitió compensar tal degradación del lenguaje. Esta capacidad compensatoria de la literatura radica en haber hecho del lenguaje un principio en sí mismo, generando con ello un repliegue del lenguaje sobre su propio origen. En consecuencia, el lenguaje literario pasa a operar según un principio de pura superficialidad que hace que toda exégesis de este remita a su propia condición de articulación significante, sin suponer un sentido oculto o primero al que habría de tributar. El doble movimiento epistémico en que se vio envuelto el lenguaje a fines del siglo XIX condujo a dos destinos posibles: una formalización que aspiraba a su absoluta transparencia como medio de relación con la realidad, la que encontraría su epítome en Bertrand Russell, y el repliegue del lenguaje sobre su propio origen, haciendo que la interpretación sea un movimiento que no tiene más referencialidad que la del propio texto, lógica que encontraría su representante más eminente en Freud y su concepción de lo inconsciente.

El descubrimiento de lo inconsciente por parte de Freud, así como la invención de la literatura moderna -de la cual la ficción gótica forma parte- dan cuenta tanto de la episteme como de los modos de subjetivación característicos del siglo XIX. Ambas experiencias encarnan esta específica manera que tiene el lenguaje de presentarse en sí mismo, una que, aunque capaz de construir ficciones sobre un sustrato histórico que toma por referencia, expone un pliegue autorreferencial y retórico sobre el cual se funda su capacidad de representación. En ambos casos lo que vemos aparecer como estrategia reflexiva es un saber sobre aquello que se pretendía expulsado de los confines de la racionalidad ilustrada, pero que lejos de ser 
ajeno a ella es efecto de su propia operación, según la lógica específica de lo ominoso: aquello que, apareciendo en la mayor de las vecindades, mueve a una inquietud desconcertante y, en último término, aterradora.

Lo ominoso del gótico moderno, en tanto forma de horror, es el efecto de una familiaridad trocada en inquietante perplejidad, es decir, es el resultado de una extrañeza que no proviene de lo absolutamente otro, sino de una alteridad que mora en la vecindad de lo propio, en el reverso de lo íntimo. En este sentido, la ficción gótica resulta ser un índice de la metamorfosis que sufre la experiencia de la intimidad subjetiva instaurada por la Ilustración, un giro antropológico que, al hacer de lo humano objeto de interrogación, generó en este una inédita sensación de extrañamiento de sí. El terror gótico sería la representación estilizada de esta torcedura en la que lo íntimo se ve parasitado por la extrañeza.

El discurso freudiano sobre lo inconsciente vino a dar cuenta de esta misma extrañeza en lo íntimo que la estética gótica ponía de manifiesto, discurso que no es ajeno a las disquisiciones estéticas, ya que al aproximarse a ellas no encuentra sino a ese sujeto dividido y extranjero de sí que la Ilustración contribuyó a producir.

\section{PARA CONCLUIR: LA REFLEXIVIDAD HISTÓRICA DE LO OMINOSO FREUDIANO}

El texto de Freud "Lo ominoso" (1992a), publicado en 1919, comienza con una particular advertencia: se trata de una indagación en el terreno de la estética, un campo en el que Freud dice no sentirse muy a gusto, pero al que le resulta necesario aproximarse en la medida en que el psicoanálisis compartiría con la estética un objeto afín: la preocupación por las formas de la experiencia sensible.

Unheimliche, es según Freud, una palabra-concepto, una suerte de significante que contiene en su interior un sorpresivo y ambivalente núcleo semántico. Freud arribará a la conclusión de que la palabra unheimlich termina por coincidir con su término opuesto, heimlich. Si bien unheimlich alude a lo siniestro o pavoroso y heimlich a lo familiar, íntimo o doméstico, el análisis lingüístico de Freud demuestra que ambos términos, aparentemente contradictorios, terminan por converger semánticamente. Freud (1992a) se apresura a hacernos presente su conclusión: "lo ominoso es aquella variedad de lo terrorífico que se remonta a lo consabido de antiguo, a lo familiar desde hace largo tiempo" (p. 220). El tipo de horror al que Freud se refiere 
es aquel que emerge dentro de lo familiar, un desplazamiento que hace que aquello que se experimenta como cercano adquiera el cariz de un tenebroso desasosiego. Freud repara en una referencia de Friedrich Schelling que le permite precisar la naturaleza de la vivencia que intenta discernir: "unheimlich es todo lo que estando destinado a permanecer en secreto, en lo oculto, ha salido a la luz" (p. 225).

El par heimlich-unheimlich sigue una semántica que coincide con la forma de una figura espacial no orientable, es decir, de un objeto en el que no pueden distinguirse de manera taxativa orientaciones excluyentes entre sí, como dentro-fuera, arriba-abajo o derecha-izquierda. La definición de Schelling de lo ominoso, de la que se sirve Freud, es bien clara en su semántica de la continuidad espacial: lo ominoso es aquello que debiendo permanecer oculto ha salido a la luz. Oculto e interior, luz y exterioridad, dimensiones disjuntas que se vuelven parte de un continuo en la experiencia de lo ominoso. El pliegue de una palabra respecto de su significación le permite a Freud mostrar que es este mismo doblez el que se puede advertir en la impresión sensible que se le impone al sujeto ante aquella variedad del terror calificable como ominosa, es decir, una vivencia en que lo unheimlich se muestra como una variedad de lo heimlich. Lo de antiguo conocido, lo más íntimo (otra palabra que alude a una forma de espacialidad), se hace presente como una inquietante extrañeza que mueve al pavor, un pavor tanto más inquietante en la medida en que deriva de aquello que resulta propio y conocido. Jacques Lacan (2007b), tan afecto a los juegos de palabras, inventará un neologismo que permite dar cuenta de lo ominoso, un término que pone de manifiesto la condición topológica de lo inconsciente: extimidad, concepto que busca hacer patente la solución de continuidad entre las distintas formas de situar la división estructurante de lo externo y lo interno.

Desde el terreno de un análisis del discurso avant la lettre, Freud retorna al campo de la referencia estética a través de una cita al trabajo de Ernst Jentsch (1997), una de las pocas aproximaciones, en relación con este tema, que dice conocer. Freud destaca lo que para Jentsch representa una de las principales formas de las que se vale la creación literaria para despertar en el lector la impresión de lo ominoso:

Uno de los artificios más infalibles para producir efectos ominosos en el cuento literario consiste en dejar al lector en la incertidumbre sobre si una figura determinada que tiene ante sí es una persona o un autómata, y de tal suerte, además, que esa incertidumbre no ocupe el centro de su atención. (Freud, 1992a, p. 227) 
Jentsch señala que esta maniobra narrativa se ha hecho presente de forma ostensible y exitosa en la obra literaria de E. T. A Hoffmann, afirmación con la que Freud coincide, destacando en particular el cuento "El hombre de arena" de dicho autor. Esta referencia literaria nos permite seguir el rastro de un aspecto no considerado en el texto de Freud, a saber, el carácter histórico que se puede asignar al motivo de lo ominoso y su representación estética en la literatura gótica, de la cual Hoffmann es representante. Nuestra intención es poner de manifiesto que la exégesis estética freudiana puede situarse dentro de los márgenes de una reflexión sobre las condiciones de producción histórica del sujeto; creemos que no puede pasarse por alto el hecho de que el análisis sobre lo ominoso de Freud descansa sobre un modo de representación estética representativo del espíritu de una época, y que, como tal, da cuenta de determinados modos de subjetivación histórica.

$\mathrm{Si}$, siguiendo a Freud, definimos lo ominoso como aquella forma del terror que se experimenta cuando lo oculto aflora a la luz, podemos afirmar que la dimensión ominosa de la novela gótica es la manifestación de un lastre del que la modernidad busca librarse, pero que porfiadamente retorna bajo la forma de espectros que acosan y opacan el brillo de la nueva razón. Podemos recordar aquí las ideas de Foucault (1998) en Historia de la locura en la época clásica, cuando señala un corte que no es solo epistémico, sino también subjetivante, entre la locura y la razón; si la razón científica introdujo una cesura en el diálogo con la locura, vemos que en la ficción gótica retorna una voz que cuestiona el imperio de la lógica y de la razón, poniendo de manifiesto los excedentes no tramitables de las pasiones humanas que una nueva forma de pensamiento no alcanza ni a comprender ni a acallar del todo.

En este sentido, creemos que la concepción freudiana de lo ominoso, aunque Freud parece no haber estado advertido de ello, da cuenta de una forma de la experiencia sensible que emerge dentro de determinadas coordenadas históricas, precisamente porque aquello a lo que se refiere es una forma de vivencia subjetiva que resulta viable en los márgenes de la nueva racionalidad de la época. En este sentido podemos interpretar el aserto lacaniano de que el sujeto del psicoanálisis es el sujeto de la ciencia: “(...) es impensable que el psicoanálisis como práctica, que el inconsciente, el de Freud, como descubrimiento, hubiesen tenido lugar antes del nacimiento, en el siglo que ha sido llamado el siglo del genio, el XVII, de la ciencia (...)" (Lacan, 2009, pp. 814-815).

Para Jean-Claude Milner (1996) lo que trasunta la hipótesis de Lacan es 
un cartesianismo radical, que hace del cogito el fundamento absoluto del sujeto moderno. Este sujeto no se define ya por ninguna individualidad empírica ni por las cualidades de un alma, de manera que "no tiene ni sí mismo ni reflexividad ni conciencia" (Milner, 1996, p. 42). El cartesianismo radical de Lacan implica suponer que el sujeto de la ciencia es puro pensamiento desustancializado, es decir, su ser es únicamente la presencia de un pensar sin cualidades. Este sujeto, drásticamente determinado por el cogito, es tan necesario para la ciencia moderna como para el psicoanálisis. Como sostiene Milner, el pensamiento en la tradición de la ciencia no resulta ya un corolario de la conciencia de sí -condición que también está en la base del descubrimiento freudiano-, lo cual podría resumirse según la siguiente fórmula: allí donde no hay un yo puede haber pensamiento, afirmación que encuentra una de sus evidencias más palmarias en la Traumdeutung freudiana.

Podemos decir entonces que las operaciones que dieron origen al sujeto de la ciencia crearon las condiciones para una representación estética que es propia de la modernidad, a saber, la naturaleza ominosa del terror gótico. Precisamente en el lugar de advenimiento de un sujeto que se define por su pensar, en un gesto que desaloja las referencias sustanciales brindadas por las tradiciones religiosas y monárquicas, vemos emerger una forma de ficción que expone el revés del pensamiento ilustrado: temores, pasiones y desviaciones que afloran frente a un sujeto que supuestamente ya no se encontraba concernido por las sombras que la luz de la razón habría hecho desaparecer. Lo que debe ser advertido, y de ahí su carácter ominoso, es que estas formas de horror aparecen doblemente vinculadas a este nuevo sujeto. Por una parte, lo acosan más por su cercanía y afinidad que por su extranjería; no se trata ya de una monstruosidad que proviene de los confines de lo humano o lo divino, sino de figuras que son próximas y semejantes o, directamente, internas. Pensemos, por ejemplo, en la figura del vampiro, un ser que fue un hombre y que ha sido arrojado a la infamia por perseverar en lo más humano que hay en él, el amor. O una criatura como Frankenstein, cuyo clamor es una exigencia de filiación paterna a su creador; y, por último, los personajes del Dr. Jekyll y Mr. Hyde, de la nouvelle de Robert Louis Stevenson, los que alegóricamente pretenden exponer la interioridad irreductible de la perversidad en el ser humano. En todos estos casos vemos surgir el horror dentro de los lindes de lo más próximo de la experiencia humana, en otras palabras, son figuras de lo ominoso en tanto en ellas apreciamos que lo siniestro se encuentra en una relación de proximidad o familiaridad de la que deriva su particular talante. Por otra parte, 
otra dimensión común de la fantasía literaria gótica es que el horror al que ella nos aproxima es consecuencia de un desafío al orden de la naturaleza o lo divino; los ejemplos recién expuestos atestiguan sobre esto: el vampiro es el resultado de una transgresión a la voluntad divina, Frankenstein y Mr. Hyde son el resultado de una provocación científica que sobrepasa los límites de la creación que eran el privilegio de la naturaleza y el espíritu. La transgresión en que se funda la posibilidad de lo ominoso gótico encuentra su marco de inteligibilidad en las condiciones promovidas por la matriz ideológica de la Ilustración, un marco en que se pone de manifiesto el doble movimiento de afirmación y negación de la agencia humana que la ciencia moderna viene a producir, la que hace del humano el punto de fuga donde converge una nueva potencia de descubrimiento y creación, pero que, simultáneamente, pone en evidencia la degradación de su supremacía respecto del resto de lo existente. La ciencia, al develar que la humanidad ya no es aquel modo de existencia constituido a imagen y semejanza de dios, le arrebata el espejo que le devolvía al humano un reflejo reconfortante y tranquilizador.

Freud, en un breve texto de 1917, titulado "Una dificultad del psicoanálisis" (1992b), hace referencia a las tres graves afrentas que ha recibido "el amor propio de la humanidad" por parte de la ciencia: la afrenta cosmológica que Copérnico en el siglo XVI le inflige al señalar que la Tierra no es el centro del universo; la afrenta biológica propinada por la teoría de Darwin que, al ubicar al ser humano en la misma posición que cualquier otra criatura viviente, lo destrona de la posición de privilegio que suponía tener respecto de todas las demás especies y, finalmente, la afrenta psicológica que el descubrimiento de lo inconsciente significó, descubrimiento que puso de manifiesto que la conciencia de sí, supuestamente consustancial al ser humano, "tropieza con límites a su poder en su propia casa, el alma" (Freud, 1992b, p. 133).

Es precisamente la dimensión narcisista de la constitución del sujeto otro de los aspectos que a juicio de Freud son centrales para la comprensión de la experiencia estética de lo ominoso. Tomando como apoyo un trabajo de Otto Rank publicado en $1914^{3}$, Freud alude al carácter ominoso de la figura del doble, un motivo muy frecuente en la literatura de terror gótico, pero que además se extiende a otras formas de la monstruosidad que, sin

\footnotetext{
${ }^{3}$ El trabajo de Otto Rank referido por Freud es “Der Doppelgänger", publicado en la revista Imago $\mathrm{N}^{\circ} 3$, de 1914 .
} 
ser dobles en sentido estricto, operan dentro de la lógica especular del semejante. Para Freud (1992a) la dimensión del doble ha

nacido sobre el terreno del irrestricto amor por sí mismo (...) que gobierna la vida anímica tanto del niño como del primitivo; con la superación de esta fase cambia el signo del doble: de un seguro de supervivencia, pasa a ser el ominoso anunciador de la muerte. (p. 235)

Si la evolución histórica implicó, como hemos sostenido, un debilitamiento de los referentes imaginarios que ubicaban lo humano en un lugar de privilegio -aquel narcisismo universal al que Freud se refiere-, la figura especular del doble adquiere su carácter ominoso una vez que las condiciones de la época lo hacen pasar de ser "un seguro de supervivencia" a ser el "anunciador de la muerte". La vecindad benigna del doble, propia de estadios más tempranos del desarrollo cultural y psíquico, una vez vencidos y desalojados los poderes de la omnipotencia narcisista, se torna en amenaza, la presencia fantasmagórica de aquello que antes estuvo vivo y que tras su declinación se vuelve una potencia persecutoria. Freud (1992a), haciendo uso de otro recurso estético literario, se apoya en una referencia al texto Los dioses en el exilio ${ }^{4}$-del poeta romántico alemán Heinrich Heine-, para terminar de desarrollar su hipótesis acerca de la transmutación de la figura del doble, en lo que parece ser un ejercicio de reflexividad histórica del que no se percata, dice: "El doble ha devenido una figura terrorífica del mismo modo como los dioses, tras la ruina de su religión, se convierten en demonios" (p. 236). Podemos jugar con la referencia freudiana a Heine, y terminar por concluir que en el apogeo de la razón ilustrada los demonios de la pasión, la locura y la incertidumbre, esos espectros surgidos en el ocaso de la religión, mantienen no solo su acoso aterrorizante, sino que también nos tientan con nuevas formas de (dis)placer estético.

\section{REFERENCIAS}

Axelsson, K. (2007). The Sublime: Precursors and British Eighteenth-Century Conceptions. Oxford, United Kingdom: Peter Lang.

Bennet, A \& Royle, N. (2009). An introduction to literature, criticism and theory, 4 a edic. Nueva York, United States: Routledge.

\footnotetext{
${ }^{4}$ El texto de Heine Los dioses en el exilio fue publicado el año 1853 en la Revue des Deux Mondes en París.
} 
Botting, F. (1999). The Gothic production of the unconscious. En Byron, G. y Punter, D. (eds.). Spectral readings, towards a gothic geography (pp. 11-36). London, United Kingdom: Palgrave Macmillan.

Botting, F. (2012). In gothic darkly: heterotopia, history, culture. En Punter, D. (ed.). A new companion to the gothic (pp. 13-24). Chichester, United Kingdom: Wiley-Blackwell.

Burke, E. (1998). A philosophical enquiry into the origin of our ideas of the sublime and beautiful (Oxford World's Classics). Reading, United Kingdom: Oxford University Press.

Cixous, H. (1976). Fiction and Its Phantoms: A Reading of Freud's Das Unheimliche (The "Uncanny"). New Literary History 7(3), 525-645.

Derrida, J. (1989). La escritura y la diferencia. Barcelona, España: Anthropos.

Derrida, J. (1997). La doble sesión. La diseminación (7a edic., pp. 263-427). Madrid, España: Editorial Fundamentos.

Des Pres, T. (1983). Terror and the Sublime. Human Rights Quarterly 5(2), 135146.

Dolar, M. (1991). "Shall be with you on your wedding-night": Lacan and the uncanny. October 58, 5-23.

Ellison, D. R. (2001). Ethics and aesthetics in European modernist literature: from the sublime to the uncanny. Cambridge, United Kingdom: Cambridge University Press.

Foucault, M. (1998). Historia de la locura en la época clásica I ( $1^{\mathrm{a}}$ edic, $2^{\mathrm{a}}$ reimp.). Santafé de Bogotá, Colombia: Fondo de Cultura Económica.

Foucault, M. (2010). Las palabras y las cosas, $2^{\text {a }}$ edic. Ciudad de México, México: Siglo XXI.

Freud, S. (1992a). Lo ominoso. Obras completas Tomo XVII (1917-19) (pp. 215251). Buenos Aires, Argentina: Amorrortu.

Freud, S. (1992b). Una dificultad del psicoanálisis. Obras completas: Tomo XVII (1917-19) (pp. 125-135). Buenos Aires, Argentina: Amorrortu.

Hogle, J. (2014). Introduction: Modernity and the proliferation of the Gothic. The Cambridge Companion to the Modern Gothic (pp. 3-19). Cambridge, United Kingdom: Cambridge University Press.

Jay, M. (1998). Cultural semantics, keywords of our time. Massachusetts, United States: The University of Massachusetts Press.

Jentsch, E. (1997). On the psychology of the uncanny (1906). Angelaki: Journal of the Theoretical Humanities 2(1), 7-16.

Kant, I. (2005). Observaciones sobre el sentimiento de lo bello y lo sublime. Madrid, España: Fondo de Cultura Económica.

Kant, I. (2007). Crítica del juicio. Madrid, España: Tecnos.

Lacan, J. (2007a). El Seminario de Jacques Lacan: libro 10: la angustia (1 ${ }^{\text {a }}$ ed., $3^{\text {a }}$ reimp.). Buenos Aires, Argentina: Paidós.

Lacan, J. (2007b). El Seminario de Jacques Lacan: libro 7: la ética del psicoanálisis ( $1^{\text {a }}$ ed., $10^{\text {a }}$ reimp.). Buenos Aires, Argentina: Paidós. 
Lacan, J. (2009). La ciencia y la verdad. Escritos 2, (3a edic., pp. 813-834). Ciudad de México, México: Siglo XXI.

Lynch, D. S. (2008). Gothic fiction. En Maxwell, R. y Trumpener, K. (eds.). The cambridge companion to fiction in the romantic period (pp. 47-63). Cambridge, United Kingdom: Cambridge University Press.

Milner, J.C. (1996). La obra clara. Lacan, la ciencia, la filosofía. Buenos Aires, Argentina: Manantial.

Morris, D. B. (1985, Winter). Gothic sublimity. New literary history 16(2), 299319.

Oroño, M. (2017). Lo sublime dinámico en la tercera crítica de Kant. Eidos 27, 199-223.

Pseudo-Longino (2007). De lo sublime (Traducción de Eduardo Molina C. y Pablo Oyarzún R.; noticia preliminar, notas e índices de Pablo Oyarzun R.). Santiago, Chile: Metales Pesados.

Rank, O. (1914). Der doppelgänger; eine psychoanalytische studie. Imago 3, 97-164.

Sedgwick, E. K. (1981, Mars). The character in the veil: imagery of the surface in the gothic novel. PMLA 96(2), 255-270. 